\title{
Les activitats econòmiques dels jueus del comtat d'Empúries (1321-1325) Joel Colomer Casamitjana
}

A començaments del segle XIV el comtat d'Empúries era un territori de la Corona d'Aragó pròsper i dinàmic. La seva capital, Castelló d'Empúries, jugava un paper fonamental a l'hora de proporcionar els elements bàsics pel seu desenvolupament econòmic, comercial i social, a més del polític, lògicament. Una àmplia estructura funcionarial, amb similituds considerables amb l'organigrama governatiu dels reis de la Corona, era l'encarregada d'administrar els dominis del comte i d'imposar la legislació existent. Una amalgama de personatges relacionats amb el món de la judicatura, agents econòmics i comercials, menestrals, professionals de tota mena, residien i donaven vida a Castelló. Era una situació que apuntava des de finals del segle XIII, quan Castelló ja era un punt neuràlgic i central del nord-est del Principat, i que a inicis del Tres-cents es va acabar de consolidar.

La fira de Rams i els dies de mercat a Castelló eren moments de visita obligada per a una gran quantitat de comerciants i homes d'afers del territori. Les trobades comercials propiciaven una preeminència econòmica del comtat en relació amb altres zones de la Corona i fins i tot de la Mediterrània. S'hi feien intercanvis de tota mena de productes, préstec de diners, formalització d'operacions comercials que traspassaven les fronteres del regne i donaven lloc a tractes, contractes i formalitzacions de pactes que es registraven a les notaries de la vila de Castelló. Les oficines dels notaris i escrivents de la vila vivien moments d'autèntica ebullició i això ens proporciona una rica mina d'informació: els registres notarials de la vila permeten de fer-se càrrec del volum de mercaderies que es movien a Castelló i estudiar-ne l'evolució. La riquesa documental dels volums conservats és una clau fonamental per dur a terme una anàlisi minuciosa de diferents aspectes de la societat empordanesa del moment (Fort, Serna \& Soler 2001 i 2004).

De la resta de viles i nuclis urbans del comtat cal destacar Peralada, que sota el domini del vescomte Rocabertí, vassall del comte d'Empúries, també va tenir un paper estratègic respecte al constant creixement de l'economia del comtat (Farías 2009), sobretot gràcies a l'especialització comercial en l'àmbit de la draperia. La venda i transacció de teixits va permetre la proliferació de professionals relacionats amb el ram del tèxtil: paraires, drapers, teixidors, tintorers, i d'altres, residien a la vila de Peralada i hi van establir els seus obradors.

Per altra banda, els professionals dedicats a altres activitats també tenen reservada una parcella de protagonisme als documents i conformen un teixit empresarial integrat i plenament relacionat amb el seu entorn més immediat, d'un 
abast local i regional. Sabaters, carnissers, picapedrers, mercaders, professionals del crèdit, entre d'altres, feien de Peralada un dels nuclis urbans més punters del comtat, després de la capital. L'àrea d'influència territorial apareix delimitada per la procedència dels personatges que formalitzen documents a la notaria de Peralada. Sobretot van ser els habitants de les parròquies i les petites viles del nord-oest del comtat els que s'arribaven a Peralada per obtenir diferents serveis, productes o establir relacions amb altres individus.

Un factor clau per al dinamisme del comtat va ser la presència de jueus a diferents nuclis urbans del territori. La comunitat jueva més important va ser l'aljama de Castelló. S'hi va concentrar la major part dels jueus del comtat, a més d'erigir-se com aljama amb privilegis ja concedits

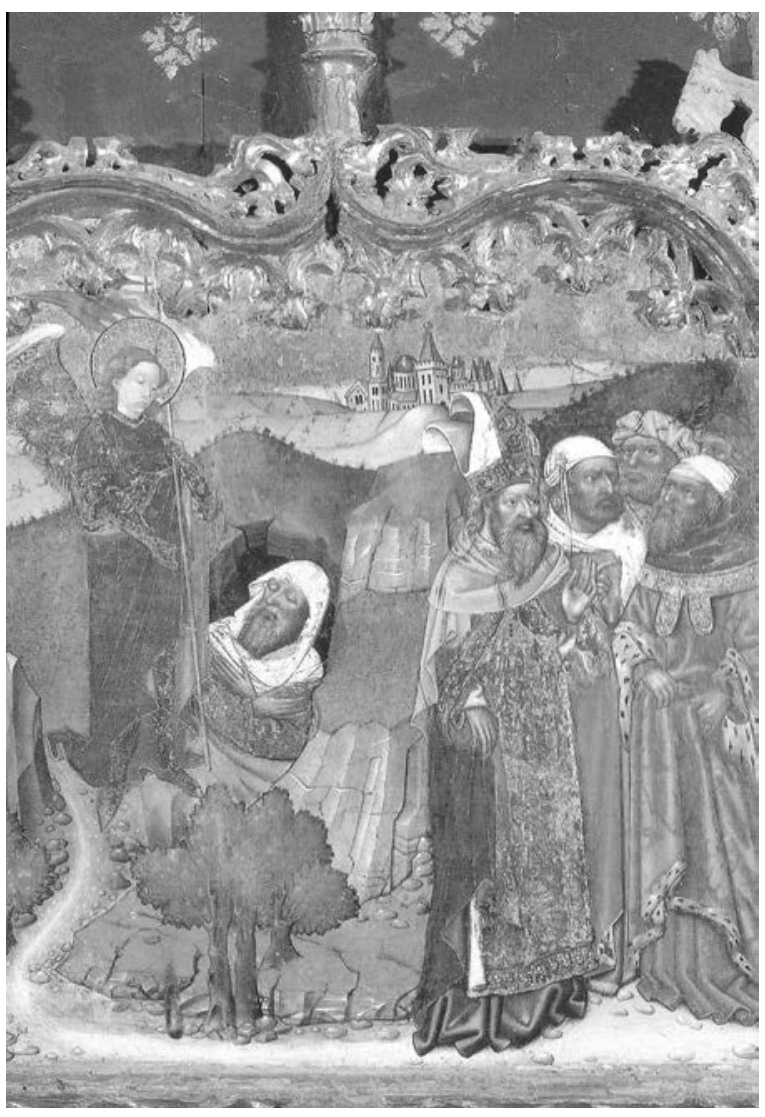

a la primera meitat del Grup de jueus notables castellonins ben vestits i amb cara de presegle XIII. El comte Ponç ocupació al costat de l'arcàngel Miquel, vetllant el cos exànime de Hug III concedí 1238 un Moisès. Retaule de st. Miquel a Castelló d'Empúries, obra de Joan (1238 un Antigó, Honorat Borrassà i Francesc Vergós (Girona, Museu d’Art privilegi de constitució de segle xv).

l'aljama de Castelló, sens dubte, un dels privilegis més antics de la Corona d'Aragó localitzats fins a dia d'avui (Bensch 2008a). Per constituir-se com a tal, la comunitat jueva de Castelló disposava de sinagoga, sens dubte l'eix central de gran part de la vida dels integrants de l'aljama, on s'hi dirimien els afers socials, polítics d'estructuració interna i sobretot les cerimònies relacionades amb la pràctica de la religió jueva. A més, cal destacar que els jueus de Castelló depenien exclusivament del comte d'Empúries i en cap cas formaven part de la jurisdicció del rei, com ho testimonien alguns manaments reials conservats. És Pere el Cerimoniós qui ordena a un dels seus oficials que els jueus del comtat
d'Empúries restin sota la protecció del comte. Com a conseqüència, els oficials reials no tenien potestat sobre ells i no els podien obligar a retre comptes al patrimoni reial, ni impartir-hi justícia, tal i com feien, en canvi, a la gran majoria d'aljames de la Corona d'Aragó (Pujol 2002: 24).

Tanmateix cal analitzar quin és el nivell d'incidència dels jueus en el desenvolupament del procés que va permetre Castelló d'Empúries esdevenir un punt neuràlgic i estratègic en els afers comercials del comtat. La comunitat jueva de Castelló estava formada aproximadament per uns 300 individus (Pujol 2002: 13), però cal tenir en compte també els jueus que residien en altres viles del comtat.' Les connexions entre jueus de diferents aljames eren freqüents i habituals, en forma de pactes matrimonials, procures, establiment de societats, etc. El conjunt dels documents que s'hi refereixen permeten veure la xarxa especialment complexa que creaven els jueus de diversos nuclis urbans. Malgrat que la mobilitat responia a criteris diversos, sobretot depenia de les activitats econòmiques, les relacions socials i la preponderància política a l'interior de les comunitats jueves existents.

\footnotetext{
1 Tal com explica Farías (2004), els jueus de Peralada van formar una petita comunitat, d'unes deu famílies, sense constituir una aljama ni rebre privilegis del vescomte Rocabertí. Tanmateix sembla que era habitual que algunes famílies optessin per installar-se en determinades viles o nuclis urbans per desenvolupar els seus negocis, principalment relacionats amb el món financer $\mathrm{i}$ del crèdit local.
} 
Castelló d'Empúries no va ser una excepció i les famílies jueves que hi vivien van teixir una gran quantitat de vincles amb famílies d'altres localitats. Aquestes connexions traspassaven territoris i jurisdiccions, fins i tot regnes. Les relacions entre individus i famílies de diferents territoris era un dels trets que identificava la cultura jueva: la pertinença a una família i a una comunitat van esdevenir pilars bàsics de la seva existència. Viure en comunitat els identificava com a collectiu unit i homogeni dins una societat majoritàriament cristiana. Tot i que en algunes ocasions els jueus notaven i percebien el rebuig frontal d'aquesta majoria, la coexistència era necessària per a tots i al comtat d'Empúries la comunitat jueva va tenir un paper central en l'estructuració de la societat.

\section{Els documents}

Per estudiar l'evolució de l'economia i la societat empordanesa de principis del segle XIV existeix una documentació excepcional. Els arxius notarials de Castelló d'Empúries, però també els d'altres viles i parròquies del mateix comtat, són extraordinàriament rics i interessants per a la seva explotació històrica. Proporcionen una gran quantitat de dades, de noms de personatges, de situacions, d'operacions, de mecanismes, que permeten fer-se una idea força acurada de la realitat del comtat el 1300. Lògicament els jueus ocupen un lloc destacat en els milers de notes documentals inscrites a les notaries de Castelló. Pel que fa a les tipologies documentals, sobresurten els llibres específics dels contractes i activitats, fonamentalment econòmiques, dels jueus de l'aljama, els anomenats instrumenta iudeorum, libri iudeorum o llibres de jueus, dels quals es compten de forma seriada, ja des de principis del segle XIV fins a ben entrat el 1400 (Llop 2013).

Per a aquest estudi, els registres consultats han estat els del notari de Castelló, Pere Perrí, i un llibre particular d'una de les famílies més conegudes de la vila, els Ravaia (Colomer 2013). Cronològicament s'han escollit els volums corresponents als anys 1322-1323 i 1325-1326. Es complementa la informació donada pels instrumenta iudeorum amb el buidatge exhaustiu d'unes altres tipologies existents a les notaries de Castelló,

\section{ELS JUEUS I EL PRÉSTEC}

El paper dels jueus en el món del crèdit és un aspecte que s'ha tractat especialment en la historiografia medieval sobre el judaisme, i més concretament per a l'àrea de Girona (Emery 1959, Guilleré 1984, Grau 1997, Mercader 1999, Soldevila 2000, Pujol 2002, Farías 2004, Bensch 2008b, Colomer 2013: n. 25). Resulta habitual comprovar que l'existència d'una aljama tenia un fort impacte sobre l'economia local. Els jueus eren un actor financer de primer ordre, sobretot alguns membres destacats de la comunitat. L'espai on aquesta preponderància és més evident són precisament les àrees rurals de la Corona. La vila mercat com a nucli central de la regió desenvolupava un rol d'atracció de població i d'oferta de productes. Sens dubte, un d'aquests era el crèdit, del qual alguns jueus eren especialistes. Tampoc en aquest aspecte el cas de Castelló d'Empúries no va ser una excepció, sobretot si tenim en compte la seva vitalitat econòmica i mercantil des de finals del segle XIII. Els jueus de la comunitat castellonenca eren famosos per algunes activitats, però determinats personatges sobresortiren per la seva capacitat d'oferir crèdit. Préstec a curt i mitjà termini, que en moltes ocasions s'acabava convertint a llarg termini, per a un públic molt específic, la ruralia de l'entorn de la capital del comtat.

dels anys 1325-1326, els intus villam (contractes entre gent de la mateixa vila de Castelló), els comunium (contractes comuns diversos) i els extra villam (contractes entre gent de fora de la vila de Castelló), del notari Bernat Jonquer (Fort 2001: $35)^{2}$

2 Els registres instrumenta iudeorum analitzats són del notari Pere Perrí, regs. 427,42, 43, 430. I el reg. 44 que correspon al llibre particular de Jaffia Ravaia i el seu fill Vidal (1323-1331). Del mateix Pere Perrí el reg. 44 bis, comunium. De Bernat Jonquer, notari de Castelló, els llibres extra villam, regs. 116, 117, 119, 413 i 369; els intus villam, regs. 368, 118, 121, 122. 
Evidentment, l'elecció d'aquesta cronologia no és gratuïta. El motiu principal és poder veure, copsar i analitzar de forma detallada l'impacte de la carestia de cereals que va patir la Corona d'Aragó durant els anys 1325-1326. Especialment virulenta va ser l'afectació de l'accés als cereals per mala collita a la demarcació de Girona, tal com ho testimonien algunes institucions de l'època, com ara el Consell municipal de Barcelona (Cáceres 2007: 115). Afortunadament, les fonts permeten examinar com va afrontar l'Empordà, una de les zones de major producció de cereals de la Corona, l'atzucac d'aquests anys. Per tal d'avançar en l'estudi d'una situació tan interessant, l'objectiu d'aquest treball és resseguir les operacions dels agents econòmics i les estratègies comercials i mercantils que van aplicar per encarar-la. Els jueus hi van tenir una participació activa que es pot desglossar en una gamma d'activitats, de la venda i transacció de cereals a l'aportació de crèdit i la concessió de préstecs als habitants de Castelló i de la resta del comtat. D'altra banda, la documentació també permet fer un cop d'ull a les altres ocupacions professionals que tenien els jueus de la comunitat, i ens dóna accés a l'anàlisi d'un ampli ventall de situacions viscudes i d'evolucions personals. Gràcies a aquestes fonts, doncs, podrem resseguir l'activitat d'alguns dels professionals jueus més influents de l'aljama i de la societat castellonina a la primera meitat del segle XIV.

\section{Els personatges}

Amb una mostra documental dels mesos de setembre a desembre del 1322 i de gener i febrer del 1323 hem pogut reconstruir l'organització del préstec jueu de la comunitat de Castelló. Els instrumenta iudeorum proporcionen una quantitat d'informació ingent i el nombre total de préstecs registrats en aquest semestre és d'unes 500 operacions. La tipologia documental utilitzada pels jueus en la formalització dels préstecs eren els anomenats mutua, una modalitat de crèdit que consistia en el reconeixement del deute a favor del creditor per una quantitat de diners determinada (en sous melgoresos), l'establiment d'uns terminis de devolució i d'unes garanties (personals o materials), si s'esqueia. Era necessari que uns testimonis donessin fe del contracte. Seria el cas de Berenguer Miralles i la seva muller Astruga, i Joan Mestre, habitants de la vila de Castelló, els quals reconeixen deure a Juceff de Colliure, jueu de Castelló, 22 sous a tornar en un any.3

Per analitzar l'impacte i la repercussió del crèdit jueu sobre el territori és interessant l'aplicació del mètode prosopogràfic. Per exemple, alguns membres de la família Bonastruc, com Momet, Juceff i Sutllam, apareixen habitualment entre els creditors jueus. La seva àrea d'influència s'estén pel conjunt de parròquies i viles petites del sud del comtat, com ara Sant Pere Pescador, l'Armentera o Torroella de Fluvià, poblacions amb una presència considerable de pagesos, pescadors i altres professionals rurals necessitats de crèdit. Es registren un total de 69 préstecs formalitzats pels Bonastruc a favor dels habitants rurals que requerien diner líquid per satisfer les seves necessitats més bàsiques orientades al consum o per fer front a inversions de les seves explotacions agràries o negocis. La quantitat total de diners prestats per aquesta família de jueus castellonencs ascendeix als 5.244 sous melgoresos, unes sumes gens menyspreables en només sis mesos d'activitat.

El cas paradigmàtic és el de la família Ravaia (Colomer 2013: 65-69). Les operacions les signen Jaffia i el seu fill Vidal, dos destacats membres de l'aljama de Castelló, que apareixen amb assiduiitat a la documentació connectada amb els afers de la comunitat. En els mesos analitzats es documenten més de cent operacions de crèdit relacionades amb diferents personatges del comtat, a favor dels Ravaia, fonamentalment per la zona de Sant Pere de Pescador, Riumors, Far i Castelló. El nombre total de sous prestats és d'uns 8.100 sous, amb un decalatge que va des dels 11 sous del préstec més modest als 500 sous del més important. Aquestes xifres posen de manifest l'enorme capacitat financera d'aquests personatges i sobretot la manera d'estructurar el seu negoci. Els múltiples contractes amb diferents clients els obligava a tenir un control molt estricte i constant de les operacions efectuades.

3 Arxiu Històric de Girona, Notarials Castelló, Pere Perrí, Instrumenta iudeorum, reg.42, 12 gener 1322. A partir d'ara AHG, Notari, reg., foli o data. 
El paper del notari i de tots els oficials del comtat era fonamental per tal de garantir el retorn dels diners pactats. Per altra banda, també eren personatges amb una alta capacitat de negociació. Les situacions particulars, sobretot dels deutors, feia que en determinades ocasions s'optés per allargaments de períodes i terminis de pagament, renegociacions de quantitats, pagaments parcials dels deutes, etc. En definitiva, s'emprava tota una maquinària creditícia l'estructura interna de la qual podem estudiar i conèixer de primera mà gràcies a la documentació notarial conservada. Sens dubte, els préstecs de diners no eren només simples transaccions econòmiques, sinó que afavorien l'establiment de vincles i relacions de caire social. El contacte entre els diferents agents del mercat feia que els lligams entre persones fos explícit i real.

\section{El mercat de productes alimentaris}

Per tal de copsar la reacció de la societat empordanesa davant d'aquest moment de dificultat, hem posat el punt vine, f. 15v, s. xiv/3). de mira en l'anàlisi de l'evolució de les operacions comercials dels jueus que apareixen en la documentació. Tal com s'ha vist, en els instrumenta iudeorum la major part dels contractes inscrits es refereixen a préstecs de diners. De totes maneres, el que és interessant en el cas de Castelló, i per extensió del comtat, és que també dediquen part de la seves inversions al mercat dels productes alimentaris. Els seus interessos se centren en tres productes agraris de primer ordre: els cereals (forment, ordi), el raïm i l'oli. Recordem que els cereals eren la base de la dieta de la societat medieval, tal com posen de manifesten estudis dedicats a la història de l'alimentació (Riera 1993). Els més apreciats eren el forment (per fer el pa blanc i de major qualitat), l'ordi, de menor qualitat però molt habitual, i el mill. En segon lloc, el raïm, directament relacionat amb la producció del vi, que va ser un producte molt conreat al comtat d'Empúries. Totes les transaccions analitzades en aquest sector estan protagonitzades per jueus, atès que no s'ha trobat cap venda de raïm feta per un cristià. Aquesta dada permet fer-se una idea de la influència que els jueus exercien també en la compravenda de determinats productes en mercats com el de Castelló. El tercer i últim producte que atreia l'interès dels jueus és l'oli, un producte central en la vida de la societat medieval atesa la seva versatilitat i les múltiples funcions que tenia: es feia servir en la illuminació de les llars i de les habitacions, però també en indústries com la dels teixits. Finalment, i en menor mesura, també apareixen alguns contractes de compravenda de llegums. 
En la conjuntura estudiada és interessant constatar que la presència dels jueus en el mercat d'aliments és més palesa en moments de dificultat, de males collites o d'accés restringit als productes esmentats. Precisament els anys 13251326 en són un bon exemple i Castelló un laboratori perfecte per observar-ho.

\section{QUADRE I - LES TRANSACCIONS DE PRODUCTES ALIMENTARIS A CASTELLÓ D’EMPÚRIES}

\begin{tabular}{|l|r|r|r|r|}
\hline & 1323 & 1325 & 1326 & Total \\
\hline Cereals & 130 & 169 & 246 & 545 \\
\hline Oli & 6 & 14 & 3 & 23 \\
\hline Raïm & 41 & 36 & 20 & 97 \\
\hline Altres & 1 & 0 & 0 & 1 \\
\hline Total & 178 & 219 & 269 & 666 \\
\hline
\end{tabular}

Font: elaboració pròpia

De totes maneres, els cereals esdevenen el producte que més contractes genera a la notaria $i$ en el nombre global de vendes representen un percentatge elevat respecte de la resta. El 1326 és l'any on es registren més contractes, un total de 246, coincidint amb el moment en què es viu amb més intensitat la carestia provocada per la mala collita de l'estiu de l'any anterior. La clientela principal de les compres de cereals són els pagesos de les parròquies del comtat que han d'accedir al mercat per poder obtenir llavors per plantar i productes de consum propi, ja que les seves collites no els abasteixen suficientment.

A partir del mes de gener de 1325, els instrumenta iudeorum registren un alt nombre de vendes de petites quantitats de cereals per part de pagesos del comtat a jueus de la vila de Castelló. Es tracta de documents que fan constar la quantitat de cereals venuda i el preu de la transacció per mitgera o quartera de forment o ordi. El termini sempre és el mateix: la festivitat de Sant Feliu (1 d'agost). Les vendes es concentren en els mesos de gener-maig de l'any 1325, període en què ja se sap si al juliol la collita serà bona o no. Per exemple, Castelló Torrenter i la seva muller Berenguera, de la parròquia de l'Armentera, venen dues mitgeres de forment al jueu de Castelló, Benvenist Juceff, pel preu de sis sous. Així

\section{ELS METGES I EL MÓN DE LA MEDICINA}

El paper dels jueus en el món de la medicina és un tema d'estudi molt suggestiu que es mereix un petit apunt sobre el cas castelloní. Tot i les dificultats que tenien per poder accedir als estudis reglats de les diferents universitats existents, la seva expertesa com a metges era més que coneguda i preuada (McVaugh 2011-2012). La documentació notarial denomina els jueus relacionats amb la medicina de diverses maneres: magister phisicus, medicus, phisicus, etc. A Castelló, un dels metges habituals en la documentació és mestre Vidal de Mercadell, magister phisicus (AHG, Pere Perrí, reg.50, 11 agost 1329) (McVaugh 2011-2012: 15). La seva nòmina de pacients era llarga i sobretot molt selecta. Membres de l'alta aristocràcia i la noblesa, no només del comtat de Castelló, sinó d'altres parts del regne i de la cort reial. (Alguns dels personatges que va tractar van ser Hug de Cardona, comte d'Empúries entre els anys 1322-1325, abans de l'entrada de l'infant Pere (AHG, Pere Perrí, reg.54, 30 agost 1331); Bernat de Sarrià, noble i gran almirall ja amb el rei Jaume I, del qual rebé grans honors. Va seguir vinculat a la Corona i sempre al servei dels successius reis (AHG, Pere Perrí, reg.47, 31 agost 1328); o Bernat de Sant Martí, ciutadà de Lleida (AHG, Pere Perrí, reg.429, 31 octubre 1337.) Les procures que signa amb diferents personatges per tal de cobrar deutes pendents és la tipologia documental que ens informa més sovint de les activitats de mestre Vidal de Mercadell. Coneixem els deutors dels contractes, és a dir els seus pacients i les quantitats totals o parcials que cobrava pels seus serveis.

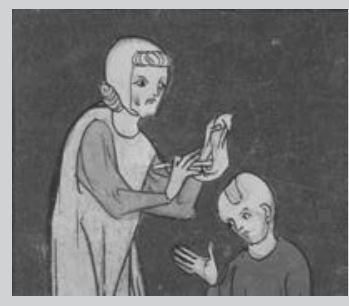


doncs, el preu unitari de cada una de les mitgeres de forment és de tres sous. El termini d'entrega de la quantitat de cereal és per Sant Feliu, moment de la collita (AHG, Pere Perrí, reg.43, 15 gener 1325). Mitjançant aquestes operacions, els jueus devien comprar cereal per avançat, a un preu inferior que no el podrien adquirir en el període de la collita durant una mala anyada, com va ser el cas del 1325. Posteriorment devien vendre el cereal a un preu més alt, gràcies a la forta demanda ocasionada per l'escassetat del mercat. El procés descrit posa en evidència que es tractava d'operacions mercantils de caràcter especulatiu.

\section{QUADRE 2 - LES VENDES DE CEREALS DE PAGESOS A JUEUS DE LA COMUNITAT DE CASTELLÓ}

\begin{tabular}{|l|r|r|r|}
\hline & 1325 & 1326 & Total \\
\hline Vendes & 141 & 56 & 197 \\
\hline Cereals (mitgeres/quarteres) & 400 & 167 & 567 \\
\hline Quantitat sous & 1.275 & 769 & 2.044 \\
\hline
\end{tabular}

Font: elaboració pròpia

Posteriorment, a partir de la tardor del $1325 \mathrm{i}$ sobretot durant l'any 1326 , els jueus actuen a la inversa. Procedeixen a la venda dels seus actius de cereals acumulats, lògicament a un preu superior. És probable que el fet de no especificar el preu exacte per mitgera o quartera en els contractes fos un detall que tenia la intenció d'ocultar les pràctiques especulatives amb el preu dels cereals, davant de les suspicàcies que podien despertar. Els beneficis obtinguts en aquests operacions justificaven les inversions de la primavera del 1325 en la compra de cereals de forma avançada. Els rendiments que obtenien els jueus al mercat de cereals complementaven els beneficis derivats del negoci del préstec de diners.

\section{QUADRE 3 - LES VENDES DE CEREALS FETES PER JUEUS DE LA COMUNITAT DE CASTELLÓ}

\begin{tabular}{|l|r|r|r|}
\hline Compres & 1325 & 1326 & Total \\
\hline Debitoris & 18 & 42 & 60 \\
\hline Sous & 631 & 1.288 & 1.919 \\
\hline
\end{tabular}

Font: elaboració pròpia
Si es calcula la diferència entre els diners invertits pels jueus en les compres de cereals abans de la collita i les quantitats obtingudes de les vendes fetes, sobretot, al llarg de l'any 1326, el benefici obtingut se situa en un $26 \%$. Per tant, la inversió de part dels seus recursos financers en el mercat dels cereals era un negoci ben profitós per al qual valia la pena reservar capital. Les dades analitzades demostren que els jueus tenien informació i habilitat, sabien invertir en el moment oportú i adequat, i coneixen les idiosincràsies de mercats com el dels cereals.

Finalment, cal remarcar que l'anàlisi de la mostra estudiada (anys 1325-1326) trenca una sèrie de tòpics en relació amb les activitats $i$ la vida dels jueus. En primer lloc, el 72\% dels contractes referents a transaccions de cereals a Castelló van ser protagonitzats per jueus, un percentatge que fa evident que alguns membres de la comunitat jueva de Castelló coneixien millor el mercat dels cereals del comtat que els cristians. Així doncs, la vinculació dels jueus amb sectors no financers de l'economia local resulta evident. Per altra banda, també es pot posar en dubte el compliment de les ordres dels consells municipals de viles i ciutats de la Corona segons els quals els jueus no podien tocar amb les mans els aliments venuts al mercat (Riera 1988).

\section{Els contractes de corallers}

A Castelló també s'han localitzat contractes relacionats amb el món del corall i la seva explotació comercial. Són testimonis interessants que posen de manifest que els jueus tenien una especial habilitat a l'hora de comerciar amb béns delicats com el corall. Atès que Castelló era una vila propera a la costa i hi treballaven professionals dedicats als oficis relacionats amb el mar, el corall era un producte habitual al mercat de la vila. N'és un exemple el contracte comercial que l'any 1323 el noble Galceran de Begur formalitza amb un jueu de Castelló, Mossé Artay (AHG, Pere Perrí, reg.42, f. 82v.). És un préstec mutuum, per valor de cent sous, que el noble reconeix deure al 
jueu. S'especifica que per garantir el retorn dels diners prestats, el noble obliga l'impost sobre el corall que cobra als seus dominis i que, juntament amb altres productes, es fa portar al port de Begur. També s'estableix que en cas de no pagament dels diners per part de Galceran, aquest respondrà amb el corall esmentat. El jueu prestava diners, com tants d'altres, però exigia com a garantia un dels productes que ell treballava especialment, tal com veurem més endavant. Per altra banda, les vinculacions comercials d'aquesta índole eren freqüents i formaven part del dia a dia de la societat empordanesa medieval.

Seguint amb la mateixa família Artay de Castelló, el mateix any apareixen com a propietaris d'un obrador on es treballava el corall. Pel funcionament ordinari del negoci necessitaven mà d'obra especialitzada en el tractament del corall. S'inscriu un contracte d'aprenentatge i el més interessant és que la representant del taller és una jueva, Druda, muller de Mossé Artay, que reconeix rebre al seu taller, en qualitat d'aprenents, Jacob Barral, jueu, i la seva muller Avineta. ${ }^{4}$ Provenen del sud de França i es comprometen a «ad I annum continue completum ad operandum et faciendum operis necessarias in corallo tam de die quam de nocte») ("per un any complet podrà fer i realitzar les tasques necessàries en el treball del corall, tant de dia com de nit'). Per tant, Jacob Barral i la seva muller devien ser experts en la manipulació i l'art del corall. En el document queden reflectits els pactes i les clàusules, sobretot les tasques a desenvolupar i l'instrumental de què disposaven, com ara la quantitat de llenys necessària. Curiosament, mig any abans Jacob Astruch, jueu de Marsella també va ser contractat per Mossé Artay perquè treballés al seu obrador ( $\mathrm{Pu}$ jol 2002: 240). En aquest cas el pacte era per dos anys i en el contracte s'especifica que si durant aquest temps necessita més personal, l'haurà de llogar. Sembla que va ser el cas, ja que, al cap de sis mesos, efectivament els Artay han de fer-se amb els serveis del matrimoni Barral, cosa que demostra que el negoci devia prosperar.

4 AHG, Pere Perrí, reg. 42, f. 101r, 6 juny 1323. A la ciutat de Barcelona, Anna Rich identifica algunes famílies jueves relacionades amb el treball $\mathrm{i}$ el comerç del corall. (Rich 1999: 142-150).

\section{Conclusions}

Els jueus del comtat, i més concretament els de la vila de Castelló, van ser de vital importància per a l'esdevenidor del territori i pel seu desenvolupament econòmic i comercial. L'aportació de capital mitjançant el préstec, majoritàriament rural, va fer possible que les famílies pageses poguessin tirar endavant les seves explotacions agràries, però també que els menestrals de Castelló o de viles menors tinguessin l'oportunitat d'invertir en els seus negocis o d'impulsar els seus projectes econòmics.

No obstant això, la documentació notarial mostra que els jueus tenien més interessos a part del préstec i que invertien diners i temps en altres mercats, especialment en el dels productes alimentaris i, més concretament, en els cereals. Els guanys que obtenien de les inversions en aquest mercat i la manera com gestionaven les seves operacions demostra que eren un dels agents més importants, gràcies a l'ús que feien de la informació sobre el funcionament de la producció i venda de cereals.

Altres ocupacions professionals habituals dels jueus són les relacionades amb el món de la medicina, que ja s'ha tractat de manera clara en d'altres casos. Una cultura molt lligada a l'estudi i a la lectura dels textos, com la jueva, fomentava sens dubte la formació de metges i físics amb una expertesa fora de dubte. Més curiós és el cas estudiat del treball del corall, producte que per la seva fragilitat i delicadesa requeria la contractació de professionals molt especialitzats. Tot centrat en un vila, poderosa, dinàmica i plena de color, com el vermell vigorós del corall. 


\section{Bibliografia citada}

BeNsCH, Stephen P., 2008a: «A baronial aljama: the Jews of Empúries in the thirteenth century», Jewish History, $22,19-51$.

Bensch, Stephen, P., 2008b: «La projecció regional del call de Girona al segle tretze: una visió des d'Amer i Castelló d’Empúries», Temps i Espais de la Girona Jueva, ed. Sílvia Planas, Girona: Patronat Call de Girona, 231-242.

CÁCERES, Juanjo, 2007: La participació del consell municipal en l'aprovisionament cerealer de la ciutat de Barcelona, Barcelona: Universitat de Barcelona, tesi doctoral inèdita.

Colomer, Joel, 2013: «El crèdit a Castelló a principis del segle XIV: Els Ravaia. La comunitat jueva de Castelló, cofre e tresor del comte», Jueus del rei i del comte. Homenatge a Miquel Pujol Canelles (Girona i Castelló d'Empúries, 2012), ed. Lídia Donat, Girona: Patronat Call de Girona, 51-70.

EMERY, Richard W., 1959: The Jews of Perpignan in the Thirteenth Century. Study Based on Notarial Records, Nova York: Columbia University Press.

Farías, Víctor, 2004: «ludei de Petralata. Un estudi sobre les activitats econòmiques dels jueus d'una vila catalana a l'entorn del 1300», Actes del I Congrés per a l'Estudi dels Jueus en Territori de Llengua Catalana (Barcelona-Girona, 2001), Barcelona: Universitat de Barcelona.
FARíAs, Víctor, 2009: El mas i la vila a la Catalunya medieval. Els fonaments d'una societat senyorialitzada (segles XI-XIV), València: Publicacions de la Universitat de València.

ForT, Joan, Erika SERna \& Santi SOler, 2001: Catàleg dels protocols del districte de Figueres (I), Barcelona: Fundació Noguera.

ForT, Joan, Erika Serna \& Santi SOler, 2004: Catàleg dels protocols del districte de Figueres (II), Barcelona: Fundació Noguera.

Grau montserrat, Manuel, 1997: La judería de Besalú (Girona). Siglos XIII al $x v$, Olot: Fundació Pere Simón.

Guilleré, Christian, 1984: «Le crédit à Gerone au début du XIve siècle (1321-1330)», La documentación notarial en la historia, Santiago de Compostela: Universidade de Santiago de Compostela, II, 363-380.

LLOP, Irene, 2013: «Els libri ludeorum de Castelló d'Empúries», Jueus del rei i del comte. Homenatge a Miquel Pujol Canelles (Girona i Castelló d'Empúries, 2012), ed. Lídia Donat, Girona: Patronat Call de Girona, 42-50.

McVAUGH, Michael R., 2011-2012: «El món mèdic de Castelló d'Empúries a principis del segle XIV», Mot so razo, 10-11, 7-16.

Mercader, Maria Dolors, 1999: L'aljama jueva de la Bisbal d'Empordà abans de la Pesta Negra. Els «libri iudeorum» del segle XIV, La Bisbal d'Empordà: Ajuntament de la Bisbal d'Empordà.

Pujol, Miquel, 2002: La conversió dels jueus de Castelló d'Empúries, Castelló d'Empúries: Ajuntament de Castelló d'Empúries.

RıcH, Anna, 1999: La comunitat jueva de Barcelona entre 1348 i 1391 a través de la documentació notarial, Barcelona: Fundació Noguera, 142-150.

RIERA, Antoni, 1993: «Estructura social y sistemas alimentarios en la Cataluña bajomedieval», Acta historica et archaeologica mediaevalia, 14-15, 193-217.

RierA, Jaume, 1988: «La conflictivitat de l'alimentació dels jueus medievals segles XII-XV»), Alimentació i societat a la Catalunya medieval, Barcelona: CSIC-Institució Milà i Fontanals (Annexos de l'Anuari d'Estudis Medievals, 20), 295-311.

SoldeVILA, Xavier, 2000: La comunitat jueva de Torroella de Montgrí (12701348), Torroella de Montgrí: Museu del Montgrí i del Baix Ter.

TeIXIDó, Francesc, 2009: Pesos, mides i mesures al Principat de Catalunya i comtats de Rosselló i Cerdanya a finals del segle XVı (1587-1594), Barcelona: Fundació Noguera. 


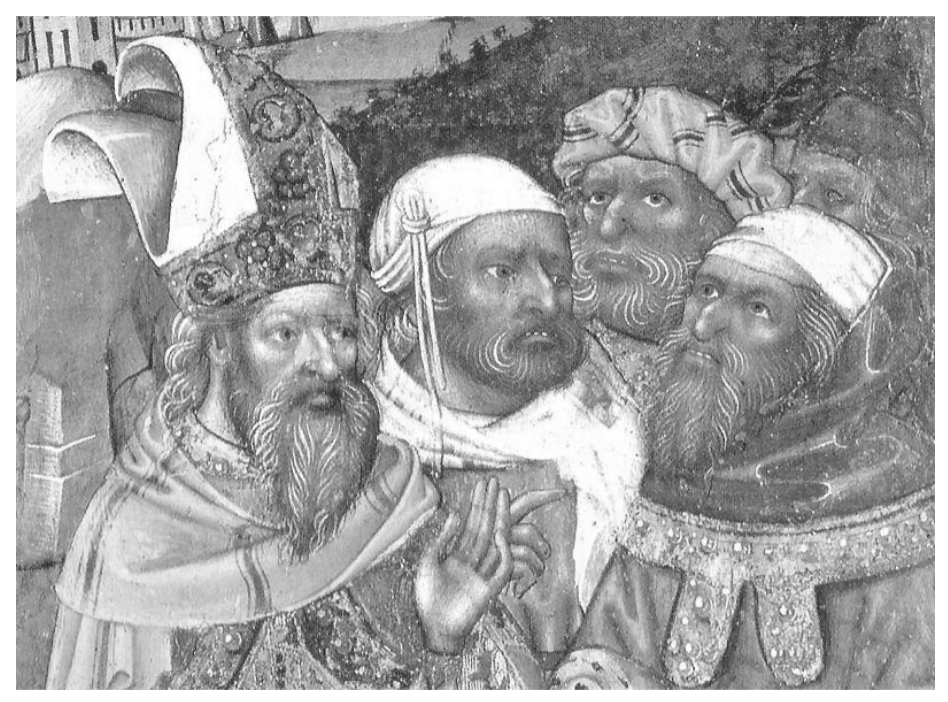

Detall del retaule de st. Miquel, a Castelló d’Empúries, obra de Joan Antigó, Honorat Borrassà i Francesc Vergós (Girona, Museu d'Art, segle xv). 
com per exemple les batalles perdudes.

Ricardo Córdoba de la Llave dedica la seva aportació a l'accés dels joves al mercat laboral (93-110). Encara que hi havia diferències entre el món urbà $i$ el rural, i entre nois i noies, en general l'accés es feia, d'una banda, mitjançant de l'aprenentatge pràctic, que es formalitzava mitjançant contractes de servei intra o extrafamiliars; i de l'altra, d'una formació intellectual que incloïa l'alfabetització i un ensenyament acadèmic adaptat a les necessitats de coneixement científic, cultural o pràctic de cada perfil professional.

Una altra perspectiva de la formació la dóna Nenad Féjic, que a «L'intégration des jeunes dans la société communale ragusaine au Moyen Âge, entre idéal et réalité» (111-126) analitza la creació d'un orfenat pel Gran Consell de la República de Dubrovnik el 1432 i l'encaix dels orfes en la quotidianitat urbana d'aquesta ciutat dalmàtica. L'autor mostra que en realitat, encara que la riquesa facilités la integració social dels joves, la diferència entre patricis i ciutadans era considerable. Conclou que l'important era l'estat i l'origen social.

Al mateix segle, però a Catalunya, la consciència de la importància de l'alfabetització ja s'havia difós fins i tot a les zones rurals. En l'article «La lectura i l'escriptura: d'una societat primitiva a una societat civilitzada. Per lo interès e bon estament de la cosa pública (diòcesi de Barcelona, segle xv)» (127-138), Josep Hernando exposa els esforços de les autoritats eclesiàstiques de Barcelona per fer arribar a tothom l'ensenyament elemental — gramàtica $i$ arts-, fins i tot als que no eren aspirants a clergues $\mathrm{i}$ als estudiants pobres, als quals se'ls assignava uns determinats veïnats perquè poguessin rebre almoina pagar els seus mestres.

Seguidament, Anne Brenon analitza un cas molt específic d'heretgia al segle XIII. El seu article "Comment un petit paysan de la montagne devient un héretique: l'enfance cathare de Guilhem Rafart, de Roquefort (avant 1225-après 1282)» (139-148) intenta traçar la biografia d'aquest home a partir de l'estudi de la influència del seu entorn familiar, en especial la seva mare, el seu lloc de creixença i la iniciació càtara en la seva infantesa.

Pel que fa a la importància del poder monàrquic i religiós, Óscar Villarroel González ofereix un estudi de la formació de les elits dirigents. En la seva aportació, «Formación para el servicio del rey y la Iglesia en la Castilla bajomedieval» (pp. 149-168), subratlla la importància del sistema universitari, capaç de formar individus en disciplines molt diverses i necessàries per als diferents serveis en l'àmbit polític, diplomàtic, mèdic i religiós.

Els homes i les dones que formaven part de les elits polítiques $i$ socials rebien una formació específica, basada sobretot en l'aprenentatge pràctic, l'ensenyança oral i l'ús de determinats textos didàctics. En l'article «La formación del caballero y la dama a través de los tratados didácticos peninsulares» (169-190), Isabel Beceiro Pita examina aquesta qüestió per gèneres: els homes es formaven sobretot per esdevenir cavallers, mentre que la formació de les dones se centrava en l'estudi de qüestions morals i religioses. Tot i així, l'autora adverteix que el sentit didàctic impregnava gairebé tota la producció medieval i que molts textos no s'adrecen específicament a un o altre gènere. $A$ més, conclou que la realitat de la formació dels cavallers i les dames va ser més complexa del que la vi- sió normativa dels tractats deixa endevinar.

En darrer lloc, a «Les universités médiévales, lieux de sociabilité et de formation morale» (191-202) Jaques Verger analitza l'entorn universitari com a institució que proporciona un determinat tipus de socialització. Segons aquest autor, el lloc que els universitaris ocupaven en la societat es fonamentava en bona part en la seva capacitat i habilitat de raonar. No obstant això, també assenyala que l'entrada a la universitat era difícil, ja que significava la descoberta de la gran ciutat i d'un entorn totalment desconegut que sovint generava solitud $\mathrm{i}$ inseguretat. Els estudiants hi adquirien autonomia i sentit de la responsabilitat, però es tractava d'un procés formatiu dur.

Per concloure, cal dir que aquesta miscelllània, tal com s'ha pogut comprovar, és una aportació rellevant i força completa a l'estudi de la història de l'educació a l'Edat Mitjana. D'una banda, cobreix bona part de les fases de formació de la personalitat, des de la infància fins a la joventut, i de l'altra abraça un ventall molt ampli de classes socials i àrees geogràfiques. Fins i tot, inclou estudis dedicats a col-lectius específics que completen el panorama dels processos d'aprenentatge i de les bases de l'ensenyament medieval.

LAURA SCHRÖDER 


\section{Abstracts}

\section{Joel Colomer, The Economic Activity of the Jews in the County of Empúries (1321-1325)}

The county of Empúries was undoubtedly one of the wealthier and more dynamic lands in the Crown of Aragon, and its capital, Castelló, enjoyed a period of splendour from the mid-13th century. The Jews were one of the groups that contributed to the economic and commercial growth, as this article analyses, focusing in particular on the Jewish community of Castelló and their role in the trade in cereals and coral. The data presented underlines the economic importance of this group, as well as their integration into the social life of Castelló.

\section{Antoni Contreras Mas, Real Fear, Royal Fear: Dreading Death by Poisoning in the Catalan and Majorcan Royal Courts}

A widespread fear of dying from poison seized the upper classes of European society in the 14th century, as the inventories of the wealthy and a growing number of treatises on this subject attest. This article surveys the social context that probably gave rise to this fear and the contents of specialised works on this subject. It also examines the range of precautions against an attempt to poison the king contained in the ordinances that ruled domestic life in the royal courts of Mallorca and the Crown of Aragon.

\section{Maxime Kamin, "Lo dous joc qu'entre amigua et aman se fais: Game as a Metaphor in Occitan and French Pastourelles}

This paper explores the use of game (joc) as a metaphor in both French and Occitan pastourelles. One of the most interesting authors in this respect is the 13th-century troubadour Johan Esteve. Comparing Occitan pastourelles with those composed by northern French trouvères, this analysis suggests both connections and diverging directions in both traditions.

\section{Sebastià Giralt, The End of a Legend: Arnau de Vilanova Regarding Magic and Astrology}

This article revises Arnau's thoughts and practice regarding magic and astrology, two core aspects in the creation of an enduring legendary image. If apocryphal works are disregarded, the attitudes he sustains in his writing are in line with those of contemporary intellectuals: a rejection of necromancy coupled with the acceptance of occult astral properties as the foundation of natural magic. These properties are put to use in his medical treatises, where astrology is also the basis for some remedies. However, none of the treatises on medical astrology that have been transmitted under his name are his.

\section{Sergi Grau, Arnau de Vilanova and the Concept of Medicine as an Aristotelian Science}

Arnau considered medicine to be an Aristotelian science, grounded on natural philosophy. However, he did not link medicine to philosophical speculation but rather conceived it as an art, a technique to be practiced by following Aristotelian principles. The ability and experience of the physician were fundamental to producing knowledge.

\section{Jaume Mensa, Dreams and Visions in Arnau de Vilanova's Spiritual Works}

Arnau de Vilanova's works include references to dreams or visions on six occasions. Two visions are concerned with the genesis of his own treatises, while two moralising dreams by two nuns, as well as dreams by King Frederic of Sicily and King Jaume II of Aragon, are reported in his Interpretatio de visionibus in somniis. His personal involvement differs, according to the source: he recounts and interprets his own dreams, merely narrates the nuns' dreams, and interprets the royal dreams. The purpose, always pragmatic, also varies, from legitimization in his visions to the exemplary function of the nuns' dreams and the political intent of the royal dreams, where a reform of the Church and Christendom is the objective. 


\section{Collaboradors}

Joel Colomer Casamitjana (Olot, 1979) és llicenciat en Història per la UdG i doctorand al Departament d'Història Medieval, Paleografia i Diplomàtica de la UB. Actualment està realitzant una tesi doctoral sobre els mecanismes de crèdit a la primera meitat del segle XIV a la Diòcesi de Girona. Els seus principals àmbits d'estudi són el crèdit i els processos d'endeutament a les zones rurals. També s'interessa per l'anàlisi i el desenvolupament de l'economia tèxtil i dels mercats alimentaris, amb una especial atenció als cereals i a les carnisseries de les viles mercat del nord-est de Catalunya.

Antoni Contreras Mas (Palma, 1951) és metge especialista en psiquiatria i historiador de la medicina, especialment de la mallorquina. Ha publicat articles sobre història de la gastronomia en diverses revistes especialitzades, ha dictat conferències sobre la gastronomia i cuina de Mallorca, ha collaborat en cursos sobre història de la cuina mallorquina a la UO de Palma i a la Escola d'Hosteleria de la UIB, i ha assessorat empreses privades. Entre les seves monografies destaquen El menjar blanc: orígenes y evolución de un plato (1996); La sobrassada de Mallorca. Cuina i cultura (2000) i La cuina i el temps (2002).

Sebastià Giralt és professor agregat de Filologia Llatina a la UAB. Doctor en Filologia Clàssica, màster en Història de la Ciència i postgrau en TIC i Educació. Ha fet estades de recerca a Boston i a la Biblioteca Vaticana (2011). La seva principal línia de recerca ha estat el corpus mèdic d'Arnau de Vilanova, de qui ha editat i estudiat escrits de medicina pràctica i d'arts ocultes, així com la pervivència en l'era moderna. També ha investigat sobre màgia medieval, tant en llatí com en llengües romàniques, i darrerament s'ha centrat en l'astròleg català Bartomeu de Tresbens. Ha traduiit Sèneca, Petroni i Arnau de Vilanova. És coordinador del Corpus digital d'Arnau de Vilanova, té una extensa experiència en humanitats digitals, tant per a la didàctica i la divulgació com per a la recerca.
Sergi Grau és llicenciat en Història i Doctor en Filosofia per la UAB. Ha cursat el Màster en Història de la Ciència (CEHIC) i actualment és investigador vinculat a la Facultat de Filosofia i Lletres de la UAB. Entre les seves publicacions destaquen: Cátaros e inquisición en los reinos hispánicos (Cátedra, 2012), L'herètica pravitat a la Corona d'Aragó (Fundació Noguera, 2015) i La invenció dels càtars (Angle, 2016). Ha rebut el Premi de Filosofia Joaquim Carreras i Artau 2017 de l'Institut d'Estudis Catalans per l'estudi Les transformacions d'Aristòtil. Filosofia natural i medicina a Montpeller: el cas d'Arnau de Vilanova.

Maxime Kamin és llicenciat en Lettres Modernes per la U. Paris-Sorbonne (2009), on també va cursar el Màster 1\&2 Littératures françaises et comparées (2011). El 2012 va fer el Màster 2 Sciences historiques, philologiques et religieuses de l'EPHE (2012). Va obtenir l'Agrégation de Lettres Modernes el 2014. Actualment és doctorand en Lettres Modernes, amb la tesi Représentations et poétiques du jeu dans la poésie médiévale, XIİ̀me-XIII'me siècles, dirigida per Estelle Doudet (U. Grenoble-Alpes).

Jaume Mensa i Valls és professor titular de Filosofia medieval de la UAB i membre numerari de l'IEC. És llicenciat (amb Premi Extraordinari) i doctor en Filosofia, llicenciat en Teologia sistemàtica, diplomat en Paleografia i arxivística (Archivio Segreto Vaticano) i ha cursat un postgrau sobre Processos Editorials. Ha centrat la seva recerca en aspectes de lògica tardomedieval (estada de recerca a La Sapienza, 1994-96), autors catalans i particularment Arnau de Vilanova, sobre els quals ha publicat diversos estudis. El seu llibre Arnau de Vilanova i les teories medievals sobre l'amor va guanyar el XXI Premi Joan Maragall (2010). El seu darrer llibrer publicat és Antoni Andreu, mestre escotista. Balanç d'un segle d'estudis (Barcelona, Institut d'Estudis Catalans, Facultat de Teologia de Catalunya, 2017). Des de l'any 2013 és el director de la revista Enrahonar. An International Journal of Theoretical and Practical Reason. 


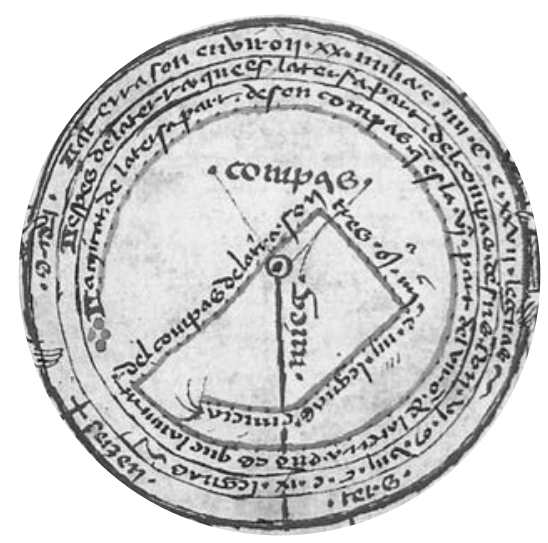

